\section{0-032 HOW LOW IS ENOUGH? - DEFINING THE THRESHOLD WITH VENOUS GRADIENT PRESSURE FOR VENOUS SINUS STENTING IN INTRACRANIAL HYPERTENSION PATIENTS WITH VENOUS SINUS STENOSIS}

${ }^{1} \mathrm{~V}$ Lopez-Rivera*, ${ }^{2} \mathrm{M}$ Inam, ${ }^{2} \mathrm{E}$ Lekka, ${ }^{2} \mathrm{~F}$ Sheriff, ${ }^{3} \mathrm{R}$ Tang, ${ }^{1} \mathrm{~S}$ Sheth, ${ }^{2} \mathrm{P}$ Chen. ${ }^{1}$ Neurolog University of Texas Health Science Center, McGovern Medical School, Houston, TX; ${ }^{2}$ Vivian L. Smith Department of Neurosurgery, University of Texas Health Science Center, McGovern Medical School, Houston, TX; ${ }^{3}$ NeuroEye Clinic, Houston, TX

\subsection{6/neurintsurg-2020-SNIS.32}

Introduction Venous stenting (VS) in the setting of intracranial hypertension with venous sinus stenosis (VSS) aids in the improvement of debilitating symptoms, such as headache, visual symptoms including visual loss, and tinnitus. However, the lowest threshold of venous sinus pressure gradient across the stenosis remains unknown for patients who would benefit from VS. We aim to compare clinical outcomes between different groups of pre-operative venous sinus gradient pressure.

Methods We prospectively collected and retrospectively reviewed data on 51 consecutive patients with symptomatic VSS who underwent VS at our center. Data on demographics, clinical presentation, lumbar puncture readings, venous pressure measurements across the stenotic sinus segment and clinical outcomes were collected and compared between 3 different groups defined by the venous sinus pressure gradient on catheter angiography, as follows: G1 (2-6 mmHg, $\mathrm{N}=19$ ), G2 (7-10 mmHg, $\mathrm{N}=14)$, and G3 (11 $\mathrm{mmHg}$ or above, $\mathrm{N}=18$ ). Continuous variables were compared by Kruskal-Wallis test and discrete variables by Fisher's exact test. Results are given as median [IQR].

Results Among 51 patients who underwent VSS, median age was 33 years [IQR, 26-37 years], 47 (92\%) were female, and median BMI was $34.85 \mathrm{~kg} / \mathrm{m}^{2}$ [IQR, 29.3-41.4 $34.85 \mathrm{~kg} / \mathrm{m}^{2}$ ]. Headache was the most common symptom on presentation (100\%), followed by visual abnormalities (96\%), papilledema (92\%), tinnitus (88\%), and optic disc atrophy (41\%). There were no differences in age, BMI, and clinical symptoms at presentation between groups. G1 had the lower post-operative venous gradient pressure $\left(\mathrm{G} 1,0 \mathrm{mmHg} \quad\left[\begin{array}{ll}0-1 & \mathrm{mmHg}\end{array}\right.\right.$; $\mathrm{p}=0.0200$ ) while $\mathrm{G} 3$ had the highest change in venous gradient pressure $(\mathrm{G} 3,12 \mathrm{mmHg}$ [11-17 $\mathrm{mmHg}] ; \mathrm{p}=0.0001)$

\begin{tabular}{lclll} 
Abstract 0-032 Table 1 & Clinical outcomes & & \\
\hline Factor, N (\%) & G1 (5-6) & G2 (7-10) & G3 (11-) & P \\
& N=19 & N=14 & N=18 & \\
\hline $\begin{array}{l}\text { 6-week follow-up } \\
\text { Headache, Resolved/Improved }\end{array}$ & $14(74)$ & $13(93)$ & $15(28)$ & 0.342 \\
$\begin{array}{l}\text { Visual abnormalities, Resolved/ } \\
\text { Improved (n=43/51) }\end{array}$ & $13 / 14(93)$ & $12 / 13(92)$ & $14 / 16(88)$ & 1.000 \\
$\begin{array}{l}\text { Papilledema, Resolved/Improved } \\
\text { (n=43/51) }\end{array}$ & $13 / 14(93)$ & $10 / 13(77)$ & $16 / 16(100)$ & 0.061 \\
$\begin{array}{l}\text { Tinnitus, Resolved/Improved } \\
\text { 6-month follow-up }\end{array}$ & $11 / 12(92)$ & $12 / 13(92)$ & $16 / 17(94)$ & 1.000 \\
$\begin{array}{l}\text { Headache, Resolved/Improved } \\
\text { (n=36/51) }\end{array}$ & $12 / 15(91)$ & $9 / 9(100)$ & $12 / 12(100)$ & 0.167 \\
$\begin{array}{l}\text { Visual abnormalities, Resolved/ } \\
\text { Improved (n=38/51) }\end{array}$ & $10 / 12(83)$ & $10 / 11(91)$ & $13 / 15(87)$ & 1.000 \\
$\begin{array}{l}\text { Papilledema, Resolved/Improved } \\
\text { (n=37/51) }\end{array}$ & $12 / 12(100)$ & $9 / 11(82)$ & $12 / 14(86)$ & 0.433 \\
$\begin{array}{l}\text { Tinnitus, Resolved/Improved (n=37/51) } \\
\text { 12/12 (100) }\end{array}$ & $11 / 12(100)$ & $11 / 15(73)$ & 0.030 \\
\hline
\end{tabular}

following treatment. At 6-week follow-up, there was no difference between the three groups in the proportion of patients who achieved improvement or resolution of their symptoms (table 1). Among patients who completed their 6-month follow-up, all patients presented with favorable outcomes, although a lower proportion of patients in G3 had a favorable outcome of tinnitus (G3, 73\%; $\mathrm{p}=0.030$ ) (table 1).

Conclusion In our cohort we found no difference in outcomes between the three groups of different venous gradient pressure cut-offs. Furthermore, patients in G1 group $(2-6 \mathrm{mmHg})$ showed to have a comparable rate of favorable outcomes, advocating that patients exhibiting a low venous sinus pressure gradient still benefit from therapy to improve their clinical course.

Disclosures V. Lopez-Rivera: None. M. Inam: None. E. Lekka: None. F. Sheriff: None. R. Tang: None. S. Sheth: None. P. Chen: None.

\section{0-033 COMPUTATIONAL FLUID DYNAMICS ANALYSIS TO COMPARE FLOW DIVERSION EFFICACY OF EVOLVE AND PIPELINE DEVICES}

${ }^{1} \mathrm{C}$ Sadasivan*, ${ }^{2} \mathrm{~B}$ Kovarovic, ${ }^{2} \mathrm{R}$ Ghosh, ${ }^{1} \mathrm{D}$ Fiorella. ${ }^{1}$ Neurological Surgery, Stony Brook University, Stony Brook, NY; ${ }^{2}$ Biomedical Engineering, Stony Brook University, Stony Brook, NY

\subsection{6/neurintsurg-2020-SNIS.33}

Introduction Flow diversion has successfully treated aneurysm patients for more than a decade. Multiple devices with design variations in composition and braid structure have been released over this time with the primary goal of intraneurysmal flow reduction. Computational fluid dynamics (CFD) studies have been the most commonly used method to evaluate the effect of different pore structures on intraneurysmal flow. The goal of this study was to use CFD analysis to compare the flow diversion behavior of the second-generation release of the Surpass flow diverter (Surpass Evolve, Stryker Neurovascular) with the latest generation Pipeline device (Pipeline Flex Embolization Device with Shield, Medtronic Neurovascular).

Methods Evolve and Pipeline flow diverters were deployed in silicone replicas of two patient-specific aneurysms (figure 1). The 'treated' replicas were scanned at a voxel resolution of 10.3 microns with a micro-CT scanner. Image slices encompassing the aneurysm neck were segmented. The centerline of each wire in the aneurysm neck region was manually traced and used to design the flow diverter covering the neck. The devices were manually registered and embedded in the aneurysm neck wall, i.e., the effect of wall apposition was not considered here. CFD was conducted in Fluent (ANSYS, Canonsburg, PA) by generating a volumetric mesh comprised of 2-4.5 Million polyhedral cells. An instantaneous, pulsatile, axisymmetric velocity profile was imposed at the cervical carotid entrance and pressures at the middle cerebral, anterior cerebral, and posterior communicating outlets were set to atmospheric. The kinetic energy of flow (velocity-squared) was averaged over the aneurysm volume at about 200 time-points over the cardiac cycle and used to compare the relative flow diversion efficacy of the two devices.

Results The figure 1 shows the streamlines near systole colorcoded by velocity for all 6 cases. A progressive qualitative reduction (from red to blue color) can be seen in the inflow 'jet' as well as intraneurysmal velocities from the Control (no 